\title{
Feline Neonatal Isoerythrolysis and the Importance of Feline Blood Types
}

\author{
Ana C. Silvestre-Ferreira ${ }^{1}$ and Josep Pastor ${ }^{2}$ \\ ${ }^{1}$ Department of Veterinary Sciences, Veterinary Hospital, University of Trás-os-Montes e Alto Douro, 5001-801 Vila Real, Portugal \\ ${ }^{2}$ Department of Animal Medicine and Surgery, Veterinary Faculty, Autonomous University of Barcelona, 08193 Bellaterra, Spain
}

Correspondence should be addressed to Ana C. Silvestre-Ferreira, aferreir@utad.pt

Received 2 October 2009; Revised 21 December 2009; Accepted 14 March 2010

Academic Editor: Giuliano Bettini

Copyright ( 2010 A. C. Silvestre-Ferreira and J. Pastor. This is an open access article distributed under the Creative Commons Attribution License, which permits unrestricted use, distribution, and reproduction in any medium, provided the original work is properly cited.

\begin{abstract}
Although feline neonatal isoerythrolysis is rare, associated mortality rate is high. It results from mating of type B blood queens with type $\mathrm{A}$ or $\mathrm{AB}$ blood toms. A comprehensive review on feline blood types and feline neonatal isoerythrolysis physiopathology, clinical features, diagnosis, treatment, and prevention is covered.
\end{abstract}

\section{Introduction}

Kitten death in the neonatal period is frequent in cat breeders [1]. Perinatal death in the first two weeks is generally associated with neonatal isoerythrolysis (NI) emaciation, congenital abnormalities, hypoglycemia, hypothermia, low weight at birth, problems during labor, ambient factors, factors related to the mother, and neonatal infections $[1,2]$. In the UK, a survey on kitten mortality (from birth to 16 weeks of age), revealed that the majority of deaths in the perinatal period (< one day) was due to NI [3]. Neonatal isoerythrolysis is believed to be a major cause of fading kitten syndrome [4]. The fading kitten syndrome is a common cause of death in the first weeks of life. It is a poorly defined syndrome, characterized by anorexia, lethargy and emaciation $[1,2]$.

Neonatal isoerythrolysis, or neonate hemolytic disease is a disease of humans and domestic animals and has been observed in cats, horses, pigs, dogs and cows. It is characterized by immune destruction of red blood cells [5]. Neonatal isoerythrolysis differs in domestic animals and humans in the fact that the syndrome is revealed at the postpartum stage in animals, and during embryogenesis in humans. Natural occurrence of NI is recognized in horses [5], cats [5-8], as well as in humans, but has been rarely identified in other species where it takes place after blood transfusions, vaccination, or previous pregnancy [5].

\section{Feline Blood Groups}

Cats have one blood group, the feline $\mathrm{AB}$ blood group system that is characterized predominantly by two blood types: type A, the most common, and type B. A third blood type is also known the rare $\mathrm{AB}$ [9]. Blood types are inherited as a simple autosomal Mendelian trait, with $\mathrm{A}$ being dominant over B. Type A blood cats may have $A A$, or $A b$ genotype. Type $\mathrm{B}$ cats are always homozygote. Little is known about the type $\mathrm{AB}$ inheritance mode which seems to be a third allele, or a case of codominance $[4,10,11]$. Although previous studies have not been definitive about the inheritance of type $A B$, a new study indicates that $A B$ is allelic to $\mathrm{A}$ and $\mathrm{B}$ in cats represented as $A>a^{a b}>b$. Possible genotypes/phenotypes would be $A A$ (Type A); $A a^{a b}$ (Type $\mathrm{A}$ ); $A b$ (Type A); $a^{a b} b$ (Type AB), and $a^{a b} a^{a b}$ (Type AB), and $b b$ (Type B) [12]. Feline neonatal isoerythrolysis (FNI) appears when type B mothers mate with type A tomcats $[1,5,6]$. Crosses between type $B$ cats only produce type $B$ kittens [4]. An important characteristic of the feline AB blood group system is the presence of naturally occurring alloantibodies against the blood type they lack. Natural means that there is no need for previous exposition to blood or blood products. All type B cats aged more than three months possess high-titer naturally occurring antiA alloantibodies with haemolysing and haemagglutinating activity, but not all of type A cats present measurable titers 
of naturally occurring anti-B alloantibodies (Table 1). In type A cats, naturally occurring anti-B alloantibodies have a feeble haemolysing and haemagglutinating activity. Type AB cats do not possess any kind of anti-AB alloantibodies [4, 9, 13]. Recently, the presence of a new alloantibody produced against a common red cell antigen was described and termed as Mik. The clinical relevance of anti-Mik alloantibodies was described as an acute hemolytic transfusion reaction after inadvertent transfusion of Mik-positive blood to the Miknegative renal transplant recipient [14].

Alloantibodies titers may suffer geographical variation (Table 1); this hypothesis is supported by data from the UK, Portugal, Spain, and Turkey where lower anti-A antibodies titers than those previously reported were found in type B cats [15-19].

The naturally occurring anti-A alloantibodies present in type B cats are responsible for FNI as well as severe red cell destruction in mismatched blood transfusions in a manner that inclusively primiparous queens may present FNI litters $[1,6,7]$.

Prevalence of FNI is unknown but it varies according to the number of type $\mathrm{B}$ cats in a given population. Feline blood types in nonpedigree cats vary geographically (Table 2). Frequency of blood types also varies among breeds (Table 3), but breed variation is not affected geographically [20-22].

Breeds like Siamese, or those genetically related, only present type A cats so the risk of FNI occurrence is null. Others, like British Shorthair, Devon Rex, Persian, Abyssinian, Turkish Angora, and Turkish Van, present type $\mathrm{B}$ cat frequencies that vary between $10 \%$ and $60 \%[21,23]$. Random mates are at a great risk of FNI in these breeds.

The gene frequencies for A and B alleles can be estimated in certain breeds by using the Hardy-Weinberg equilibrium. Assuming random mating, $q^{2}$ is the proportion of type $\mathrm{B}$ cats; $q=$ frequency of $\mathrm{B}$ allele (recessive). As for dominant allele A it corresponds to $p=1-q$; FNI $=\left(p^{2}\right)\left(q^{2}\right)+2 p q\left(q^{2}\right)$. Recently, Malik and coworkers [20] in Sidney, Australia and Arikan and coworkers [24] in Turkey, estimated, for the nonpedigree cat population, the proportion of random mating at risk of developing neonatal isoerythrolysis to be $23 \%$ and $18.6 \%$ respectively. Previously, Bücheler [25] described the risks of incompatible mating as between $14 \%$ and 25\% for Persian and Abyssinian populations.

\section{Feline Neonatal Isoerythrolysis Physiopathology}

Feline placenta is of endotheliochorial type $[6,38]$. Chorionic endothelium is closely linked to maternal capillary endothelium [38]. It only allows a small and insignificant passage of maternal antibodies, 5 to $10 \%[6,38]$. Kittens get maternal antibodies, IgG in most cases, by suckling colostrum during the first days of life $[6,7]$. The development of the immune system is a critical period for the kitten. In this period, maternal immunity is an important factor, but in some cases it can also cause disease. Kittens start to produce their own alloantibodies soon after birth, reaching their maximum level in the first months of life while the
TABle 1: Minimum anti-A antibodies titers presented by type $B$ cats and percentage of type $\mathrm{A}$ cats presenting anti-B antibodies. In all studies, all type B cats presented anti-A antibodies titers. Anti-B antibodies in type A animals ranged from $1: 2$ to $1: 16$ in most cases.

\begin{tabular}{lll}
\hline & $\begin{array}{l}\text { Minimum titers of } \\
\text { anti-A antibodies } \\
\text { presented by type B B } \\
\text { cats }\end{array}$ & $\begin{array}{l}\text { \% of type A cats } \\
\text { presenting anti-B } \\
\text { antibodies }\end{array}$ \\
\hline USA [25] & $1: 64$ & 36 \\
Australia [13] & $1: 8$ & 35 \\
Turkey & & \\
$\quad$ Pedigree [17] & $<1: 4$ & 60.6 \\
$\quad$ Nonpedigree [19] & $<1: 4$ & 70 \\
Portugal [18] & $1: 16$ & 12.5 \\
Spain (Gran Canary) [16] & $1: 16$ & 24.4 \\
United Kingdom [15] & $1: 4$ & 44.3 \\
\hline
\end{tabular}

level of maternal antibodies is low at 6 to 8 weeks $[25,39]$. FNI affects the $\mathrm{A}$, or $\mathrm{AB}$ blood type kitten, born from a $\mathrm{B}$ blood type mother by getting anti-A antibodies when it starts suckling $[1,6,7]$.

\section{Clinical Features}

FNI clinical features depend on haemolysis grade and severity. Suckling colostrum allows the passage of naturally occurring alloantibodies from mother to the neonate. Antibodies recognize the antigenic determinants in the kitten red cell surface, causing intra or extravascular haemolysis. Extravascular haemolysis can occur in the spleen or liver. Haemolysis leads to anemia, nephropathy, or disseminated intravascular coagulation $[1,7]$. Determinants to the degree of haemolysis or severity are still unknown, but the large variation in clinical signs within a litter suggests differences in colostral antibody uptake as a determinant factor $[1,40]$. Generally, kittens are born healthy and nurse energetically, but after colostrum ingestion, clinical signs appear in a few hours or days. Some may die in a few hours without presenting any kind of clinical signs. Others stop suckling in the first days of life and fade. The key signs to diagnose FNI are dark red-brown urine, indicating severe intravascular haemolysis and haemoglobinuria, but they may also present jaundice, anemia, and weakness with death occurring in the first week of life. Secondary clinical signs are pale mucous membranes and those related to decreased oxygenation: lethargy, tachycardia, tachypnea, collapse, and death. Hypoglycemia and metabolic acidosis may be present associated to stopped or decreased suckling [1]. Those who survive may develop tail tip necrosis (Table 4 ) $[1,7,8]$.

Tail tip necrosis is associated with cold IgM action, with haemagglutination, clot formation, and ischemic necrosis. In adults, due to other etiologies, ears, paws, nose, scrotum, and tail tip are usual sites of action for cold agglutinins, but in kittens, protected by the queen's body heat and because ears are folded against the head, these sites are protected; 
TABLE 2: Feline blood types geographical distribution.

\begin{tabular}{|c|c|c|c|}
\hline Country & Type A (\%) & Type B (\%) & Type AB (\%) \\
\hline Austria [26] & 88 & 12 & - \\
\hline Finland [26] & 100 & - & - \\
\hline Holland [26] & 95.8 & 4.2 & - \\
\hline Scotland [26] & 97.1 & 2.9 & - \\
\hline \multicolumn{4}{|l|}{ Denmark [27] } \\
\hline Nonpedigree & 98.1 & 1.9 & - \\
\hline Pedigree & 89.2 & 10.8 & - \\
\hline \multicolumn{4}{|l|}{ Spain } \\
\hline Barcelona [28] & 94 & 4 & 2 \\
\hline Gran Canária [16] & 85.9 & 9.4 & 4.7 \\
\hline France [29] & 85 & 15 & - \\
\hline Greece [30] & 78.3 & 20.3 & 1.4 \\
\hline Germany [31] & 93.9 & 5.4 & 0.7 \\
\hline Pedigree & 83.3 & 14.9 & 1.8 \\
\hline \multicolumn{4}{|l|}{ Hungary [32] } \\
\hline Nonpedigree & 100 & - & - \\
\hline Pedigree & 84.2 & 15.8 & - \\
\hline Italy [33] & 87.1 & 12.9 & - \\
\hline Portugal [18] & 90.3 & 3.8 & 5.9 \\
\hline Switzerland [34] & 99.6 & 0.4 & - \\
\hline \multicolumn{4}{|c|}{ United Kingdom [15] } \\
\hline Nonpedigree & 54.6 & 40.1 & 5.3 \\
\hline Pedigree & 87.1 & 7.9 & 5.0 \\
\hline \multicolumn{4}{|l|}{ Turkey [24] } \\
\hline Nonpedigree & 73.1 & 24.6 & 2.3 \\
\hline \multicolumn{4}{|l|}{ Australia } \\
\hline \multicolumn{4}{|l|}{ Nonpedigree } \\
\hline (Sidney [20]) & 62 & 36 & 1.6 \\
\hline (Brisbane [9]) & 73.3 & 26.3 & 0.4 \\
\hline Japan [35] & 90.3 & 9.7 & - \\
\hline USA [36] & 98.1 & 1.7 & 0.1 \\
\hline Nonpedigree [37] & 99.6 & 0.4 & - \\
\hline
\end{tabular}

consequently tail tip in neonatal kitten is the most vulnerable site for IgM action [8].

\section{Diagnosis}

Diagnosis is performed on the basis of clinical signs and confirmed by blood typing the queen and the kitten. If blood typing is not possible, a blood crossmatching can be performed. (Table 5; Figure 1). Kittens with FNI present a positive Coomb's test [1] which confirms the immunemediated nature of this process.

If FNI is suspected all kittens should be blood typed. At birth, cord blood from the placenta may be used to type kittens.

The crossmatching checks for serologic compatibility or incompatibility and it may be possible to detect any incompatibility, even outside the $A B$ system. This is an important advantage compared to blood typing that only recognizes blood type antigens [21]. When an incompatible
TABLe 3: Breed distribution of feline blood types; *breeds with reported type $\mathrm{AB}$ cats (Adapted from Giger [36] and Arikan and coworkers [38]).

\begin{tabular}{lcc}
\hline Breed & Type A \% & Type B \% \\
\hline Abyssinian & 84 & 16 \\
American shorthair & 100 & 0 \\
Birman* & 82 & 18 \\
British shorthair* & 64 & 36 \\
Burmese & 100 & 0 \\
Cornish Rex & 67 & 33 \\
Devon Rex & 59 & 41 \\
Exotic shorthair & 73 & 27 \\
Himalayan & 94 & 6 \\
Japanese Bobtail & 84 & 16 \\
Maine Coon & 97 & 3 \\
Norwegian Forest & 93 & 7 \\
Oriental shorthair & 100 & 0 \\
Persian & 86 & 14 \\
Scottish fold* & 81 & 19 \\
Siamese & 100 & 0 \\
Somali* & 82 & 18 \\
Sphinx* & 83 & 17 \\
Tonkinese & 100 & 0 \\
Turkish Angora & 54 & 46 \\
Turkish Van & 40 & 60 \\
\hline
\end{tabular}

TABLE 4: Key signs to FNI diagnosis.

\begin{tabular}{lc}
\hline Reaction & Signs \\
\hline Unspecific & Stop suckling $\rightarrow$ fade \\
Sudden death & Haemoglobinuria \\
Severe & Jaundice \\
Anemia & Weakness $\rightarrow$ death \\
& Decreased oxygenation \\
Lethargy \\
Tachycardia \\
Tachypnea \\
Collapse $\rightarrow$ death \\
Altered nutrition \\
Hypoglycemia \\
Metabolic acidosis \\
\hline Survivors
\end{tabular}

major crossmatching between the queen and the kitten is found, FNI may be suspected.

Nowadays for blood typing purpose, besides the traditional method, there are different commercially available methods: the card test (DMS Laboratories Inc, Flexmington, New Jersey), and the gel column technique (DiaMed AG, Cressier Sur Morat, Switzerland) [42]. Recently, two companies, in Japan and France, have introduced two novel techniques: a tube test (Shigeta Animal Pharmaceuticals Inc, 
TABLE 5: Crossmatching protocol. Major crossmatching should be compatible at $37^{\circ}$ and $24^{\circ} \mathrm{C}$ (cold agglutinins) and minor at $37^{\circ} \mathrm{C}(\mathrm{Adapted}$ from Fox [41]).

1. Collect $2 \mathrm{~mL}$ of blood into EDTA from tom/kitten and queen.

2. Centrifuge $3400 \times$ g 1 minute, separate plasma from red blood cells. Keep plasma.

3. Wash red blood cells two times, into at least twice its volume, with isotonic saline solution.

Discard supernatant and keep red blood cells.

4. Dilute red blood cells at $2 \%: 10 \mu \mathrm{L}$ washed red blood cells plus $490 \mu \mathrm{L}$ isotonic saline solution.

5. Major crossmatching:

2 drops of $(50 \mu \mathrm{L})$ tom/kitten's red blood cell dilution

2 drops of $(50 \mu \mathrm{L})$ queen's plasma

6. Minor crossmatching:

2 drops of $(50 \mu \mathrm{L})$ queen's red blood cell dilution

2 drops of $(50 \mu \mathrm{L})$ tom/kitten's plasma

7. Negative control:

2 drops of $(50 \mu \mathrm{L})$ tom/kitten's red blood cell dilution

2 drops of $(50 \mu \mathrm{L})$ tom/kitten's plasma

8. Incubate 30 minutes at $25^{\circ} \mathrm{C}$ and also at $37^{\circ}$ and $24^{\circ} \mathrm{C}$.

9. Centrifuge $3400 \times \mathrm{g} 1$ minute.

10. Examine the supernatant for any haemolysis. Any haemolysis indicates also incompatibility.

11. Rotate tubes between the fingers to mix and examine for agglutination. The presence of agglutination indicates a positive test and tom or kitten/queen incompatibility.

Oyabe City, Japan), and a new immunochromatographic cartridge (Alvedia, Lyon, France) $[42,43]$.

Most recently researchers from UC Davis have found the gene associated with the B blood group and its mutation. They developed a diagnostic DNA test so that animals can be tested at an early age from a buccal swab. The genetic test for the cat blood group identifies the recessive $b$ allele which is associated with the B serotype. This test has not been fully validated in the Ragdoll and Turkish Angora breeds, because, in some animals, results from DNA and serological tests are not concordant, but cat breeders can greatly benefit from this test for selection of mating pairs.

Necropsy is an important step in FNI and perinatal death diagnosis. As death may occur in different stages of the disease, pathological findings depend on the moment of death. The bladder may be filled with dark red-brown urine and precipitated haemoglobin. The body may appear icteric and the spleen enlarged. The spleen and liver may present marked erythrophagocytosis and extramedullar haematopoiesis. In the kidneys large red-orange tubular casts compatible with haemoglobin or acute tubular necrosis may be seen. Systemic effects of immune-mediated haemolysis, disseminated intravascular coagulation, anemia, and acute renal failure $[1,5]$, are the apparent cause of death in kittens suffering from FNI.

\section{Treatment}

FNI treatment should be aggressive and immediate. FNI treatment steps comprise replacement of passive immune protection, a blood transfusion if clinical conditions deteriorate, and life support treatment. When the first clinical signs appear, type $\mathrm{A}$ or $\mathrm{AB}$ kittens should be immediately removed from their mothers, as long as they continue to suckle more anti-A immunoglobulins they receive $[1,7]$. Type B kitten can continue to suckle. Kittens should receive immunoglobulin-rich colostrum during the first 12 hours of life to obtain optimal serum antibody titers and acquire adequate passive immune protection throughout the neonate period [7]. The interval of transfer of maternal antibodies seems to be of only 16 hours. The IgG are absorbed by the neonate during this period $[1,7]$. After this, intestinal mucosa loses its permeability, and even when administered, immunoglobulins are not absorbed [7]. Therefore, kittens only need to be removed from their mothers for the first 16 to 24 hours of life $[1,7]$. Kittens may be fed with a commercial milk replacer, previously frozen milk from a type A blood mother, or be placed with a foster type A blood queen $[1,7]$. Prevention of passive immunity failure will be addressed later on.

If anemia is severe and becomes worse, a blood transfusion should be considered. Kittens severely anemic with hypoxia signs should receive 2 to $3 \mathrm{~mL}$ of previously washed blood cells during the first 3 days of life (Figure 2). Blood donor selection is the key to a successful transfusion.

In an $\mathrm{A}$ or $\mathrm{AB}$ blood kitten with $\mathrm{FNI}$, the queen's circulating colostral antibodies are anti-A. Transfusion of type A cells simply adds more vulnerable cells to the kitten's circulation. The best blood donor would be the queen as she cannot obviously react to her own antibodies $[1,44]$.

Blood can be transfused via a spinal needle into the trochanteric fossa. ${ }^{1}$ In this way, about $90 \%$ of red blood cells are in the blood stream in 10 minutes [1, 44-46]. Due to the shortened life span of transfused red cells and a continued destruction of the kitten's own cells, anemia may worsen and a new blood transfusion may be essential. The kitten 

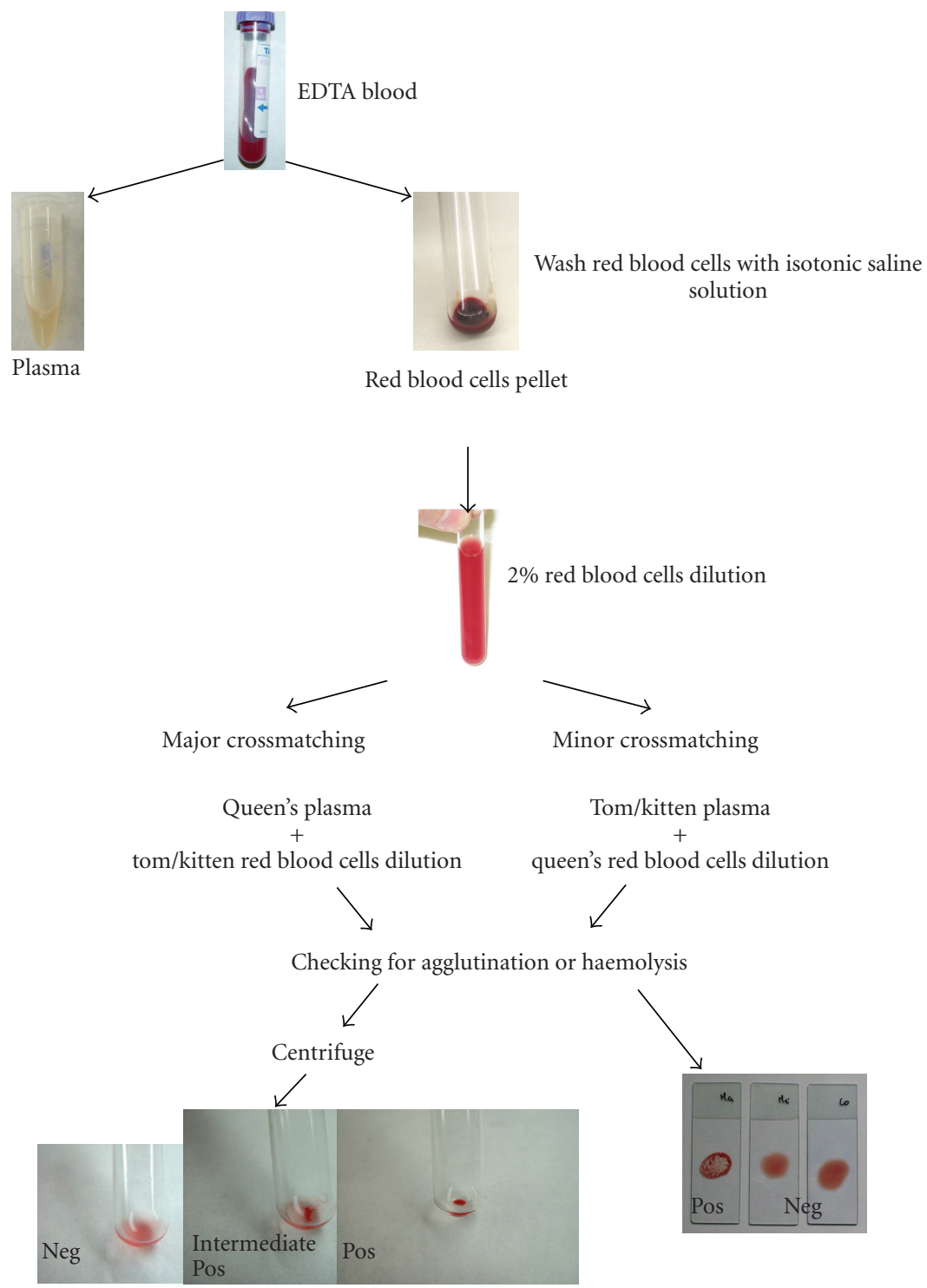

FIGURE 1: Crossmatching schematic representation. See Table 5 for procedure explanations. Crossmatching can also be performed as a slide test by using the same protocol. Haemolysis can better be recognized in the tube test when compared to slide method.

starts form its own anti-B alloantibodies soon after birth, and maternal antibodies from colostrum start to decline. Therefore, if another blood transfusion is required after 3 days postpartum, a washed type A blood administration should be considered [1]. After anemia is corrected, the kitten should receive life support treatment associated with electrolytic changes and tissular hypoxia. Even when kittens are removed from their mothers, as soon as the first clinical signs become present, the mortality rate associated with FNI is high, making prevention the most important step $[1,7]$.

\section{Prevention}

The best method to prevent FNI is to avoid incompatible mating between type B blood queens and type A blood toms. Knowledge of the parent's blood type is essential for FNI prevention. To assure blood compatibility, blood typing might be done with an in-house blood typing card, gel, or tube test, that appear to be reliable clinical laboratory methods for feline blood typing $[15,42]$, or with crossmatching $[1,7,8]$ (Table 5; Figure 1). If there is a need to mate a type B queen with a type A tom, the best way to prevent FNI is to remove the kitten from the mother for 24 hours preventing them from nursing colostrum $[7,8]$ (Table 6). Failure in passive immunity might be solved by using previously frozen colostrum, from another queen's milk $[6,7]$.

In most mammalian species, the immunoglobulin concentration in colostrum is generally much higher than that in milk [47]. Although previous studies show that milk immunoglobulin concentration in queens is similar to that present in colostrum $[6,7]$, nowadays we know that cats have 
Remove kittens from mother 16 to $24 \mathrm{~h}$ after birth

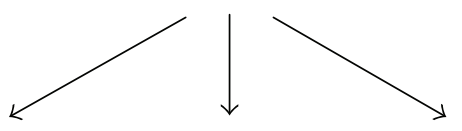

Commercial milk replacer Type A queen frozen milk Foster type A queen

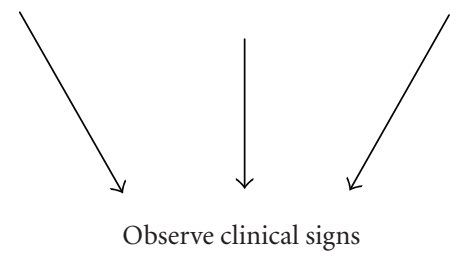

Hypoxia associated to anemia
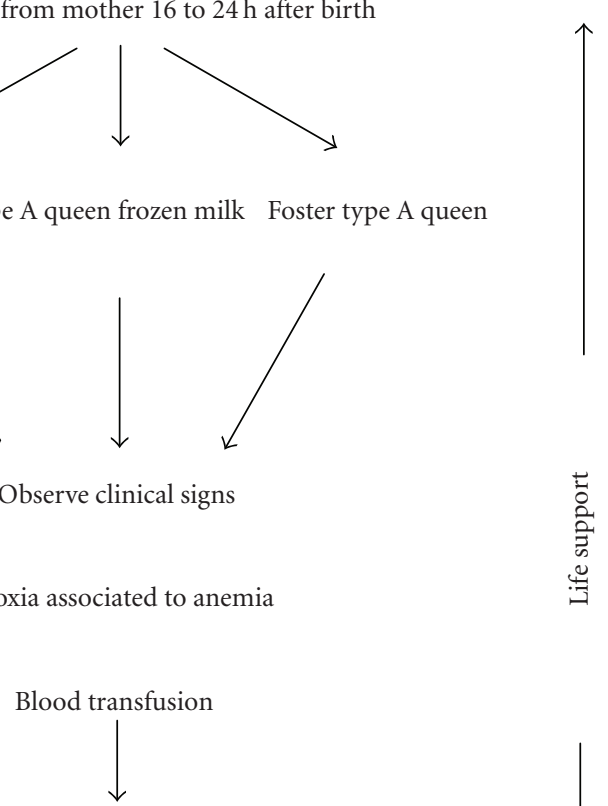

Until 3 days of birth washed type B cells

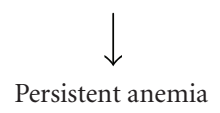

$\downarrow$

After 3 days of birth washed type A cells

FIGURE 2: Schematic representation of feline neonatal isoerythrolysis treatment. To wash red blood cells, 2 to $3 \mathrm{~mL}$ donor blood should be collected into EDTA and centrifuged; the supernatant should then be discarded. The blood is restored with isotonic saline solution into twice its volume and again centrifuged. After discarding supernatant, repeat this action and dilute cells to transfusion with an equal saline volume.

TABLE 6: Fundamental steps for feline neonatal isoerythrolysis prevention.

To know progenitors blood types by the use of blood typing and/or crossmatching.

To avoid mates between type B queens and type A toms, or not to mate type B queens.

Kittens born from mates between type B queens and type A toms should be removed from their mother on the first 24 hours of life.

both colostral and milk phases of lactation distinguished by the concentration of IgG and IgA [48]. In cats, IgG and IgA colostrum concentration is greater than that in serum, but reduced concentrations of IgG and IgA have been demonstrated in milk relative to colostrum [48]. IgM concentrations are lower in colostrum and milk than in the queens' serum [6, 7].

Although transplacentary immunoglobulin transfer is more efficient for IgG [40], fostering on queens in midlactation does not provide protective concentrations of immunoglobulins in colostrum deprived kittens [48]. A previous study also shows that parenteral administration of $150 \mathrm{~mL} / \mathrm{Kg}$ of adult feline serum results in a normal concentration of IgG in colostrum deprived kittens. Serum donors must be blood typed [49].
Another study revealed that in vitro neutrophilic and plasmatic activity hosts a defense against bacterial and other microorganisms, which is similar in kittens suckling colostrum and in those that do not suckle [50].

Because maternal IgG levels have a short life spanapproximately 4.4 days (IgG life span is shorter in kittens than in puppies) [6] and the onset of IgG and IgA production is late (IgG production starts by the 5th to 6th week of age and IgA shortly after, while, in contrast, IgM steadily increases to a plateau on the 60 th day of life) $[6,51]$, kittens are vulnerable between the third and fourth week of life. For kittens that have been deprived of colostrum, early vaccination is recommended whenever there is a risk of viral infection [7]. 
In conclusion, FNI is rare but the mortality rate is high. It results from random mating between type $\mathrm{B}$ blood queens and type A or AB blood toms. The best way to prevent FNI is to blood type progenitors, mostly those belonging to breeds with high incidence of animals with type B blood.

\section{Endnotes}

1. Cannula placement in the trochanteric fossa of the femur. Spinal needles according to animal size may be used. Neonates have soft spongy bones that can be penetrated with 18 to 25 gauge hypodermic needles. Aseptic technique must be used in preparing the access site. Make a small incision in the skin over the insertion site. For placement in the trochanteric fossa of the femur, the needle should be maneuvered off the medial aspect of the great trochanter into the trochanteric fossa. To avoid damaging the sciatic nerve, the coxofemural joint should remain in a neutral to slightly extended position with the femur externally rotated, during the placement of the cannula. Following the insertion of the cannula through the skin, pressure is applied to the needle along with firm rotation movements [45]. The stylet inside the cannula should not be removed until the blood administration starts. The stylet prevents a core of bone from obstructing the lumen during insertion [46].

\section{References}

[1] J. Bücheler, "Fading kitten syndrome and neonatal isoerythrolysis," Veterinary Clinics of North America-Small Animal Practice, vol. 29, no. 4, pp. 853-870, 1999.

[2] J. A. Roth, "Possible association of thymus dysfunction with fading syndromes in puppies and kittens," Veterinary Clinics of North America-Small Animal Practice, vol. 17, no. 3, pp. 603-616, 1987.

[3] T. A. Cave, H. Thompson, S. W. J. Reid, D. R. Hodgson, and D. D. Addie, "Kitten mortality in the United Kingdom: a retrospective analysis of 274 histopathological examinations (1986 to 2000)," Veterinary Record, vol. 151, no. 17, pp. 497$501,2002$.

[4] U. Giger, J. Bücheler, and D. F. Patterson, "Frequency and inheritance of A and B blood types in feline breeds of the United States," Journal of Heredity, vol. 82, no. 1, pp. 15-20, 1991.

[5] G. R. Cain and Y. Suzuki, "Presumptive neonatal isoerythrolysis in cats," Journal of the American Veterinary Medical Association, vol. 187, no. 1, pp. 46-48, 1985.

[6] M. L. Casal, P. F. Jezyk, and U. Giger, "Transfer of colostral antibodies from queens to their kittens," American Journal of Veterinary Research, vol. 57, no. 11, pp. 1653-1658, 1996.

[7] U. Giger and M. L. Casal, "Feline colostrum-friend or foe: maternal antibodies in queens and kittens," Journal of Reproduction and Fertility, vol. 51, pp. 313-316, 1997.

[8] K. H. Bridle and J. D. Littlewood, "Tail tip necrosis in two litters of Birman kittens," Journal of Small Animal Practice, vol. 39, no. 2, pp. 88-89, 1998.

[9] L. Auer and K. Bell, "The AB blood group system of cats," Animal Blood Groups and Biochemical Genetics, vol. 12, no. 4, pp. 287-297, 1981.
[10] M. Griot-Wenk and U. Giger, "Cats with type AB blood in the United States," Journal of Veterinary Internal Medicine, vol. 2, p. 139, 1991.

[11] M. E. Griot-Wenk, M. B. Callan, M. L. Casal, et al., "Blood type $\mathrm{AB}$ in the feline $\mathrm{AB}$ blood group system," American Journal of Veterinary Research, vol. 57, no. 10, pp. 1438-1442, 1996.

[12] B. Bighignoli, T. Niini, R. A. Grahn, et al., "Cytidine monophospho-N-acetylneuraminic acid hydroxylase (CMAH) mutations associated with the domestic cat $\mathrm{AB}$ blood group," BMC Genetics, vol. 8, no. 1, article 27, 2007.

[13] U. Giger and J. Bücheler, "Transfusion of type-A and typeB blood to cats," Journal of the American Veterinary Medical Association, vol. 198, no. 3, pp. 411-418, 1991.

[14] N. M. Weinstein, M.-C. Blais, K. Harris, D. A. Oakley, L. R. Aronson, and U. Giger, "A newly recognized blood group in domestic shorthair cats: the Mik red cell antigen," Journal of Veterinary Internal Medicine, vol. 21, no. 2, pp. 287-292, 2007.

[15] C. M. Knottenbelt, D. D. Addie, M. J. Day, and A. J. Mackin, "Determination of the prevalence of feline blood types in the UK," Journal of Small Animal Practice, vol. 40, no. 3, pp. 115$118,1999$.

[16] A. C. Silvestre-Ferreira, J. Pastor, A. P. Sousa, et al., "Blood types in the non-pedigree cat population of Gran Canaria," Veterinary Record, vol. 155, no. 24, pp. 778-779, 2004.

[17] S. Arikan and H. A. Akkan, "Titres of naturally occurring alloantibodies against feline blood group antigens in Turkish Van cats," Journal of Small Animal Practice, vol. 45, no. 6, pp. 289-292, 2004.

[18] A. C. Silvestre-Ferreira, J. Pastor, O. Almeida, and A. Montoya, "Frequencies of feline blood types in northern Portugal," Veterinary Clinical Pathology, vol. 33, no. 4, pp. 240-243, 2004.

[19] M. Gurkan, S. Arikan, E. Ozaytekin, and T. Dodurka, "Titres of alloantibodies against A and B blood types in non-pedigree domestic cats in Turkey: assessing the transfusion reaction risk," Journal of Feline Medicine and Surgery, vol. 7, no. 5, pp. 301-305, 2005.

[20] R. Malik, D. L. Griffin, J. D. White, et al., "The prevalence of feline A/B blood types in the Sydney region," Australian Veterinary Journal, vol. 83, no. 1-2, pp. 38-44, 2005.

[21] U. Giger, "Blood typing and crossmatching to ensure compatible transfusions," in Current Veterinary Therapy XIII, J. D. Bonagura, Ed., pp. 396-399, WB Saunders, Philadelphia, Pa, USA, 2000.

[22] C. M. Knottenbelt, "The feline AB blood group system and its importance in transfusion medicine," Journal of Feline Medicine and Surgery, vol. 4, no. 2, pp. 69-76, 2002.

[23] Ş. Arikan, S. Y. Duru, M. Gurkan, Z. T. Agaoglu, and U. Giger, "Blood type A and B frequencies in Turkish Van and Angora cats in Turkey," Journal of Veterinary Medicine Series A, vol. 50, no. 6, pp. 303-306, 2003.

[24] S. Arikan, M. Gurkan, E. Ozaytekin, T. Dodurka, and U. Giger, "Frequencies of blood type $\mathrm{A}, \mathrm{B}$ and $\mathrm{AB}$ in non-pedigree domestic cats in Turkey," Journal of Small Animal Practice, vol. 47, no. 1, pp. 10-13, 2006.

[25] J. Bücheler and U. Giger, "Alloantibodies against A and B blood types in cats," Veterinary Immunology and Immunopathology, vol. 38, no. 3-4, pp. 283-295, 1993.

[26] U. Giger, N. T. Gorman, M. Hubler, et al., "Frequencies of feline A and B blood types in Europe," Animal Genetics, vol. 23, pp. 17-18, 1992.

[27] A. L. Jensen, A. B. Olesen, and J. Arnbjerg, "Distribution of feline blood types detected in the Copenhagen area of Denmark," Acta Veterinaria Scandinavica, vol. 35, no. 2, pp. 121-124, 1994. 
[28] A. C. Silvestre-Ferreira, Contribución al estudio de los grupos sanguineos en felinos, Ph.D. thesis, 2005.

[29] A. Eyquem, L. Podliachouk, and P. Milot, "Blood groups in chimpanzees, horses, sheep, pigs, and other mammals," Annals of the New York Academy of Sciences, vol. 97, pp. 320-328, 1962.

[30] M. E. Mylonakis, A. F. Koutinas, M. Saridomichelakis, L. Leontidis, M. Papadogiannakis, and K. Plevraki, "Determination of the prevalence of blood types in the non-pedigree feline population in Greece," Veterinary Record, vol. 149, no. 7, pp. 213-214, 2001.

[31] C. Weingart, G. Arndt, and B. Kohn, "Prävalenz der Blutgruppen A, B und AB bei Haus- und Rassekatzen im Raum Berlin und Brandenburg," Kleintierpraxis, vol. 51, no. 4, pp. 189-197, 2006.

[32] N. Bagdi, M. Magdus, E. Leidinger, J. Leidinger, and K. Vörös, "Frequencies of feline blood types in Hungary," Acta Veterinaria Hungarica, vol. 49, no. 4, pp. 369-375, 2001.

[33] G. Lubas and R. Continanza, "Recent advances in our understanding of the immunohaematological characteristics of cats and their clinical application," European Journal of Companion Animal Practice, pp. 47-54, 1993.

[34] M. Hubler, S. Arnold, M. Casal, A. Fairburn, M. Nussbaumer, and P. Rüsch, "The blood group distribution in domestic cats in Switzerland," Schweizer Archiv fur Tierheilkunde, vol. 135, no. 8, pp. 231-235, 1993.

[35] H. Ejima, K. Kurokawa, and S. Ikemoto, "Feline red blood cell groups detected by naturally occurring isoantibody," The Japanese Journal of Veterinary Science, vol. 48, no. 5, pp. 971976, 1986.

[36] U. Giger, M. Griot-Wenk, and J. Bücheler, "Geographical variation on the feline blood type frequencies in the United States," Feline Practice, vol. 19, pp. 21-27, 1991.

[37] U. Giger, C. G. Kilrain, L. J. Filippich, and K. Bell, "Frequencies of feline blood groups in the United States," Journal of the American Veterinary Medical Association, vol. 195, no. 9, pp. 1230-1232, 1989.

[38] $\mathrm{R} \mathrm{Pu}$ and J. K. Yamamoto, "Passive transfer of maternal immunity," in Handbook of Vertebrate Immunology, P. P. Pastoret, P. Griebel, H. Bazin, and A. Govaerts, Eds., pp. 305308, Academic Press, London, UK, 1998.

[39] J. D. Hoskins, "Feline neonatal sepsis," Veterinary Clinics of North America-Small Animal Practice, vol. 23, no. 1, pp. 91100, 1993.

[40] T. Yamada, Y. Nagai, and M. Matsuda, "Changes in serum immunoglobulin values in kittens after ingestion of colostrum," American Journal of Veterinary Research, vol. 52, no. 3, pp. 393-396, 1991.

[41] L. E. Fox, "Transfusion therapy and management of the blood donor," in Consultations on Feline Internal Medicine, J. R. August, Ed., pp. 389-394, WB Saunders, Philadelphia, Pa, USA, 1991.

[42] K. Stieger, H. Palos, and U. Giger, "Comparison of various blood-typing methods for the feline AB blood group system," American Journal of Veterinary Research, vol. 66, no. 8, pp. 1393-1399, 2005.

[43] M. Seth, K. V. Jackson, and U. Giger, "Comparison of gel column, card, cartridge, slide and tube techniques for $\mathrm{AB}$ blood typing of cats," ACVIM (abstract), 2008.

[44] U. Giger, "The feline AB blood group system and incompatibility reactions," in Current Veterinary Therapy XI, R. W. Kirk, Ed., pp. 470-474, WB Saunders, Philadelphia, Pa, USA, 1992.

[45] C. M. Otto and D. T. Crowe, "Intraosseous resuscitation techniques and applications," in Current Veterinary Therapy
XI, R. W. Kirk, Ed., pp. 107-112, WB Saunders, Philadelphia, Pa, USA, 1992.

[46] D. M. Boothe and J. D. Hoskins, "Drug and blood component therapy," in Veterinary Pediatrics Dogs and Cats from Birth to Six Months, J. D. Hoskins, Ed., pp. 33-49, WB Saunders, Philadelphia, Pa, USA, 2nd edition, 1995.

[47] N. L. Norcross, "Secretion and composition of colostrum and milk," Journal of the American Veterinary Medical Association, vol. 181, no. 10, pp. 1057-1060, 1982.

[48] M. A. Claus, J. K. Levy, K. MacDonald, S. J. Tucker, and P. C. Crawford, "Immunoglobulin concentrations in feline colostrum and milk, and the requirement of colostrum for passive transfer of immunity to neonatal kittens," Journal of Feline Medicine and Surgery, vol. 8, no. 3, pp. 184-191, 2006.

[49] J. K. Levy, P. C. Crawford, W. R. Collante, and M. G. Papich, "Use of adult cat serum to correct failure of passive transfer in kittens," Journal of the American Veterinary Medical Association, vol. 219, no. 10, pp. 1401-1405, 2001.

[50] R. M. Hanel, P. C. Crawford, J. Hernandez, N. A. Benson, and J. K. Levy, "Neutrophil function and plasma opsonic capacity in colostrum-fed and colostrum-deprived neonatal kittens," American Journal of Veterinary Research, vol. 64, no. 5, pp. 538-543, 2003.

[51] M. J. Day, "Immune system development in the dogand cat," Journal of Comparative Pathology, vol. 137, pp. S10-S15, 2006. 

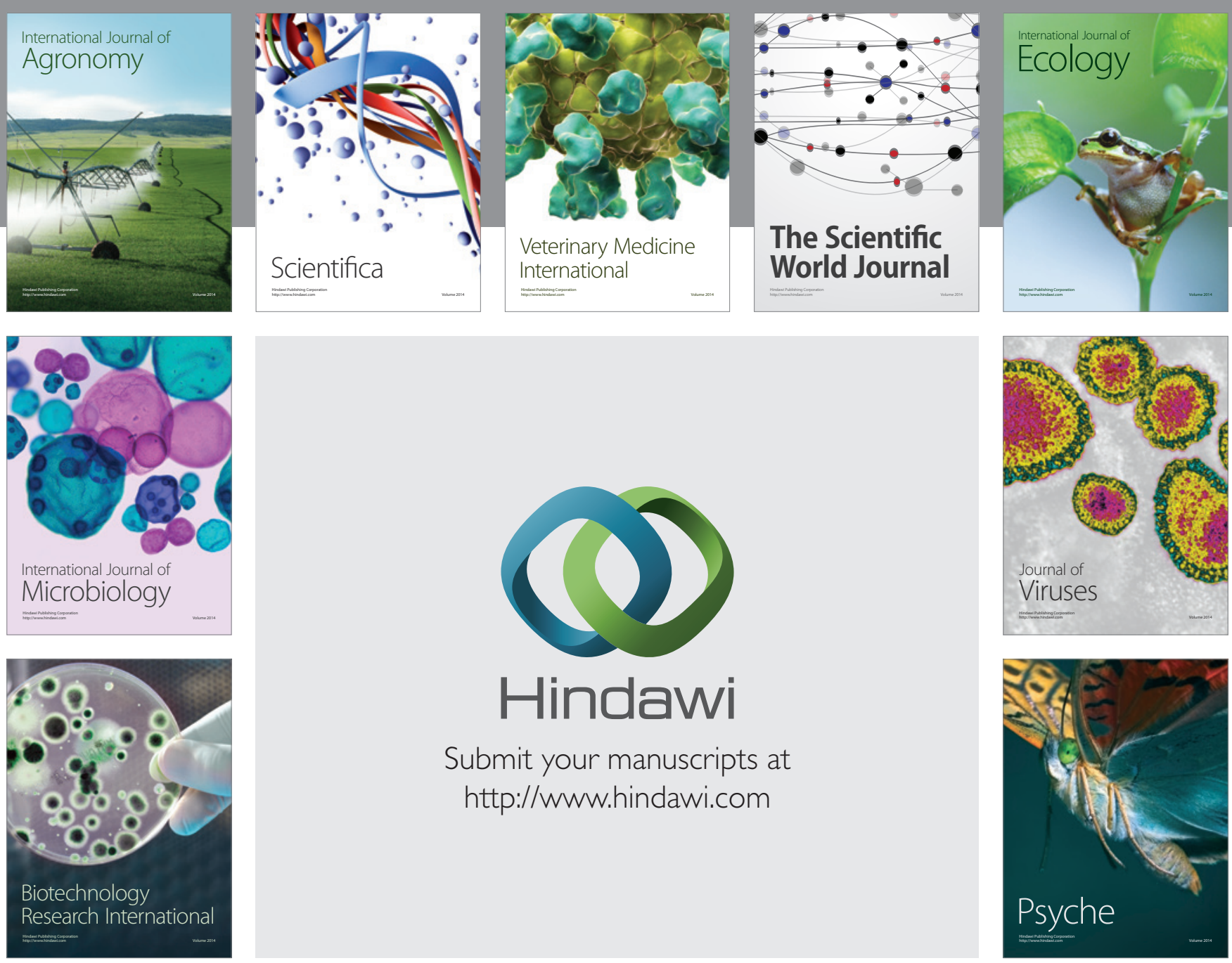

Submit your manuscripts at

http://www.hindawi.com
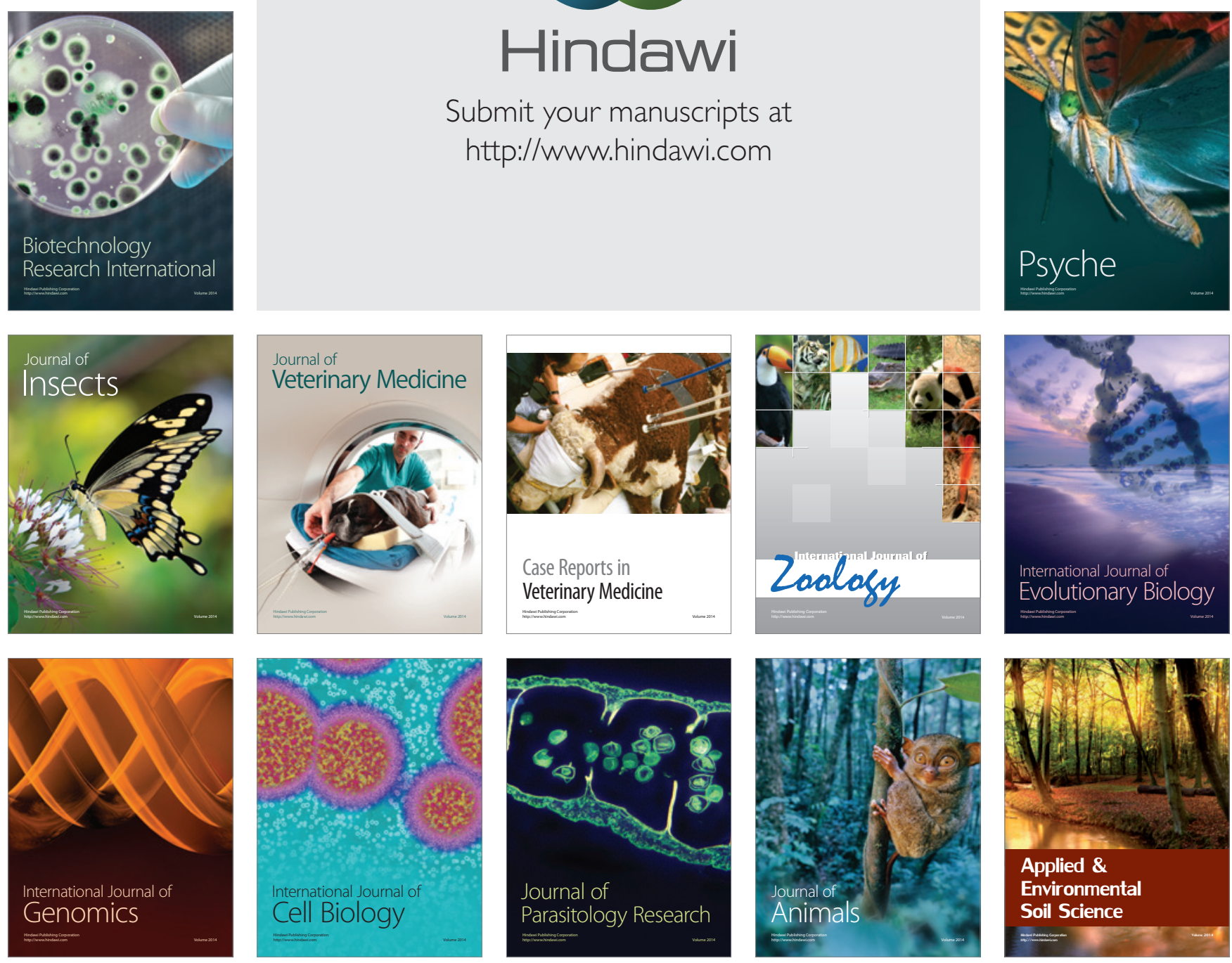